\title{
Development of Aerosol-LIBS (Laser Induced Breakdown Spectroscopy) for Real-time Monitoring of Process-induced Particles
}

\author{
Gibaek Kim ${ }^{1}$, Kyoungtae Kim², Hyunok Maeng ${ }^{1}$, Haebum Lee ${ }^{1}$, Kihong Park $^{1 *}$ \\ ${ }^{I}$ National Leading Research Laboratory, School of Environmental Science and Engineering, Gwangju Institute of Science \\ and Technology (GIST), Gwangju 61005, Korea \\ ${ }^{2}$ Memory Manufacturing Engineering Team, Semiconductor Business, Samsung Electronics Co., Ltd., Hwaseong 18448, \\ Korea
}

\begin{abstract}
Laser-induced breakdown spectroscopy (LIBS) has been increasingly used in recent years to rapidly detect the elemental compositions of various materials in different media (i.e., solids, liquids, and gases). In this study, an aerosolLIBS system was developed for the real-time monitoring of process-induced particles generated during semiconductor manufacturing. The developed system consists primarily of a laser, a spectrometer, optics, and an aerosol chamber; the last element was constructed for the application of the aerosol-LIBS to various semiconductor manufacturing processes and comprises exhaust tubes and low pressure and high temperature chambers. The system was evaluated for its sensitivity to various elements using laboratory-generated aerosols and successfully detected $\mathrm{P}, \mathrm{Fe}, \mathrm{Mg}, \mathrm{Cu}, \mathrm{Co}, \mathrm{Ni}, \mathrm{Ca}, \mathrm{Na}$, and $\mathrm{K}$ emission lines. Further evaluation of the aerosol-LIBS is ongoing.
\end{abstract}

Keywords: Laser-induced breakdown spectroscopy (LIBS); Process-induced particles; Real-time monitoring; Spectrometer.

\section{INTRODUCTION}

It has been reported that the worldwide revenue generated by semiconductor sales amounted to $\$ 333$ billion in 2016 (Park et al., 2018), and market competition is expected to gradually intensify as a result of recent growth in the electronic devices industry, which has flourished with the increased popularity of mobile phones and tablet PCs (personal computers) (Chik et al., 2010).

Various process-induced particles are generated during the semiconductor manufacturing process (Baltzinger and Delahaye, 2010; Lee and Yook, 2015), and these are responsible for approximately $75 \%$ of the total defects observed in semiconductor products (Park et al., 2018). To minimize the occurrence of defective products, the development of a real-time chemical element detection

\footnotetext{
* Corresponding author.

Tel.: 82-62-715-3279; Fax: 82-62-715-2434

E-mail address: kpark@gist.ac.kr
}

This article is an English version of "Development of Aerosol-LIBS (Laser Induced Breakdown Spectroscopy) for Real-time Monitoring of Process-induced Particles” published in Particle and Aerosol Research in September 2016. system, to detect any contaminant particles generated, is recommended, where information on the elemental compositions of any such particles is likely to be useful in revealing their sources and the mechanisms by which they are formed during the semiconductor manufacturing process (Lee et al., 2018).

Conventional methods, such as inductively coupled plasma-optical emission spectroscopy (ICP-OES) and atomic absorption spectroscopy (AAS), are usually employed to ascertain the elemental compositions of various analytes. However, these methods are relatively expensive, dilatory, and labor-intensive (Yamamoto et al., 1996; Gondal et al., 2007; Srungaram et al., 2013). Moreover, the requisite sample preparation for these methods necessitates the use of high-purity solvents, resulting in the generation of chemical waste (Bendicho et al., 2012).

In contrast, laser-induced breakdown spectroscopy (LIBS) is a relatively inexpensive and simple analytical method, requiring little or no sample pretreatment steps (Hahn and Lunden, 2000; Park et al., 2009). LIBS has hitherto been used for multi-element detection in various solid, liquid, and gaseous samples (Hahn and Lunden, 2000; Baudelet et al., 2006; Ferioli and Buckley, 2006; Harmon et al., 2009; Barreda et al., 2012; Hahn and Omenetto, 2012), and the technique boasts the ability to detect almost all of the elements of the periodic table (Cremers and Radziemski, 2006). Additionally, it has been demonstrated that the LIBS technique is applicable to particle detection (Hahn and 
Lunden, 2000; Park et al., 2009) and can perform standoff detection of hazardous materials (López-Moreno et al., 2006; Gottfried et al., 2008). Owing to its above-mentioned advantages, LIBS is applied in various fields, including environmental engineering, industry, geology, criminology, military science and space science (Park et al., 2009; Alvira et al., 2015; Grifoni et al., 2015; Lennard et al., 2015; Barefield et al., 2016; Maurice et al., 2016). Semiconductor manufacturing processes are carried out under harsh conditions (i.e., high temperatures and low pressure), and the LIBS technique can be applied in these conditions with minimal interruption to the ongoing semiconductor manufacturing process (Lee et al., 2018).

For the purposes of this study, a newly developed aerosol-LIBS system was used for the real-time monitoring of various process-induced particles generated during the semiconductor manufacturing process.

\section{METHODS}

Various laboratory-produced particles were used to examine the performance of the aerosol-LIBS developed for this study. Table 1 summarizes the experimental conditions required for aerosol generation. As may be observed, a variety of standard solutions (Sigma-Aldrich, USA) were prepared in deionized (DI) water that contained the elements $\mathrm{P}, \mathrm{Fe}, \mathrm{Mg}, \mathrm{Cu}, \mathrm{Co}, \mathrm{Ni}, \mathrm{Ca}, \mathrm{Na}$ and $\mathrm{K}$. Fig. 1 presents a schematic diagram of the aerosol-LIBS system. Aerosols were generated using an atomizer, and the droplets were dried out as they passed through a series of diffusion dryers. Subsequently, aerosols of specific sizes (nm) were selected using a differential mobility analyzer (DMA 3080; TSI Instruments; Shoreview, MN, USA) and their number concentrations $\left(\mathrm{cm}^{-3}\right)$ were monitored in real time using a condensation particle counter (CPC 3022a, TSI Instruments) (i.e., using a scanning mobility particle sizer). The aerosol-
LIBS system comprises primarily a laser, a spectrometer, optics, and an aerosol chamber. The aerosols generated were introduced into the LIBS chamber, and the spectral data obtained through the application of the aerosol-LIBS were subsequently analyzed.

A $1,064 \mathrm{~nm}$ Q-switched neodymium-doped yttrium aluminum garnet (Nd:YAG) laser (CFR 200; Quantel, France) of $200 \mathrm{~mJ}$ pulse $\mathrm{e}^{-1}$ was used as an excitation source. The laser beam was focused using a $25 \mathrm{~mm}$ focal length planoconvex lens (diameter $=20 \mathrm{~mm}$ ). Following irradiation of the aerosol with a focused laser beam, which generated the plasma, emission lines were observed as the plasma cooled. These were transferred to a spectrometer (Aurora, Applied Spectra Inc., USA) capable of analyzing the emission lines between 190 and $884 \mathrm{~nm}$. The emission lines of $\mathrm{P}(213.6 \mathrm{~nm})$, $\mathrm{Fe}(274.7 \mathrm{~nm}), \mathrm{Mg}(279.6 \mathrm{~nm}), \mathrm{Cu}(324.8 \mathrm{~nm}), \mathrm{Co}$ (345.4 nm), Ni (361.9 nm), Ca (393.4 nm), Na (588.9 nm), and $\mathrm{K}(766.5 \mathrm{~nm})$ were thus observed and analyzed. The detailed laser and spectrometer specifications and operating conditions are summarized in Table 2.

The aerosol-LIBS system was developed to facilitate its selective operation in either free-firing mode (Park et al., 2009) or triggering mode (Maeng et al., 2017). The freefiring mode can be operated in accordance with a relatively simple configuration. In this mode, aerosols are randomly ablated and then analyzed under laser firing at constant repetition rate $(1-10 \mathrm{~Hz})$. For triggering mode, however, a continuous wave $(\mathrm{CW})$ laser and a photomultiplier (PMT) are installed in addition to the fundamental LIBS system required for free-firing mode. In triggering mode, a scattering signal is detected, which is generated when the aerosol is introduced into the chamber and passes through the $\mathrm{CW}$ laser. A superior hitting rate (i.e., the number of aerosols hit by pulse laser per time) may be achieved by irradiating the pulse laser with the relevant particles according to their arrival time. This is estimated by calculating the time of

Table 1. Experimental parameters for aerosol generation.

\begin{tabular}{lll}
\hline Solution & Concentration & $0.1 \%(\mathrm{w} / \mathrm{v})$ \\
& Volume & $100 \mathrm{~mL}$ \\
& Solute & $\mathrm{Na}_{2} \mathrm{HPO}_{4}, \mathrm{FeCl}_{2}, \mathrm{MgCl}_{2}, \mathrm{CuCl}_{2}, \mathrm{CoCl}_{2}, \mathrm{NiCl}_{2}, \mathrm{CaCl}_{2}, \mathrm{NaCl}$, and $\mathrm{KCl}$ \\
\multirow{2}{*}{ Atomizer } & Operating pressure & $20 \mathrm{psi}$ \\
& Atomizing gas & Filtered air \\
\hline
\end{tabular}

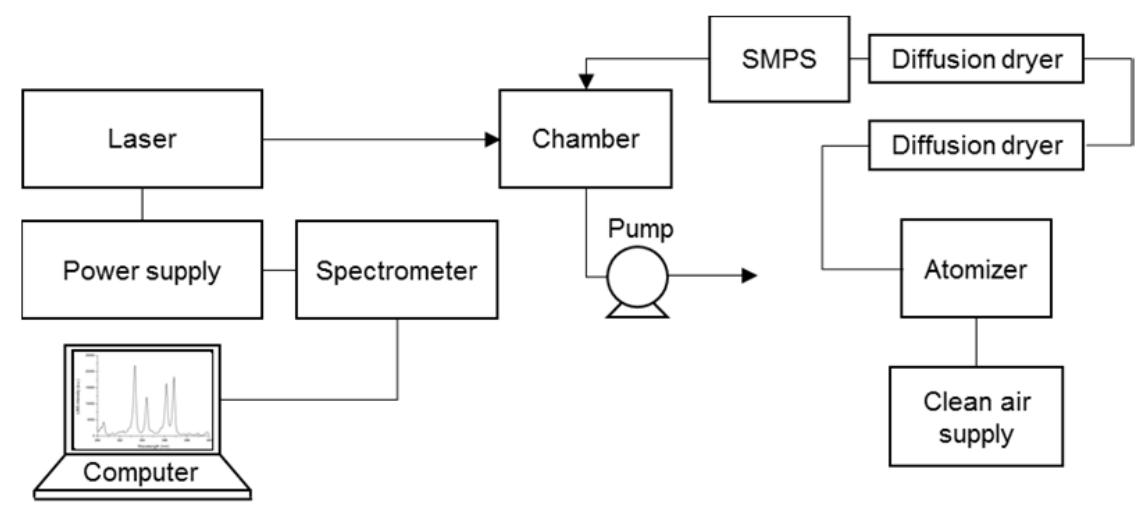

Fig. 1. A schematic diagram of the aerosol-LIBS (laser-induced breakdown spectroscopy) system. 
Table 2. Experimental parameters for LIBS analysis.

\begin{tabular}{lll}
\hline Equipment & Parameter & \\
\hline Laser & Wavelength & $1,064 \mathrm{~nm}$ \\
& Energy & $200 \mathrm{~mJ} \mathrm{pulse}^{-1}$ \\
& Pulse duration & $8 \mathrm{~ns}$ \\
Spectrometer & Repetition rate & $1 \mathrm{~Hz}$ \\
& Spectral coverage & $190-884 \mathrm{~nm}$ \\
& Resolution & $<0.1 \mathrm{~nm}$ for UV to VIS \\
& Detector type & $<0.12 \mathrm{~nm}$ for VIS to NIR \\
& Delay time & CCD linear array \\
\hline
\end{tabular}

UV, ultraviolet; VIS, visible; CCD, charge-coupled device.

arrival at the sensing point, where the pulse laser is focused on the chamber and the plasma is generated. In this paper, we present the detection properties of LIBS in free-firing mode with a newly developed portable chamber.

\section{RESULTS AND DISCUSSION}

For this study, a portable aerosol-LIBS chamber for exclusive operation in free-firing mode was developed because of its ease of installation and operation in practical application, its compatibility with various lasers, and its ease of attachment and detachment to and from the spectrometer optical cable. A sheath air-focusing nozzle was used to direct the aerosol flow toward the center of the chamber (Fig. 2).

As illustrated in Fig. 3, the path of the pulse laser was optimized by comparing the hitting efficiencies of the pulsed laser and the $\mathrm{CaCl}_{2}$ particles according to the path via which the pulsed laser was directed into the portable aerosol-LIBS chamber.

To evaluate the simultaneous multi-element detection properties of the aerosol-LIBS system, aerosols using standard solutions of $\mathrm{P}, \mathrm{Fe}, \mathrm{Mg}, \mathrm{Cu}, \mathrm{Co}, \mathrm{Ni}, \mathrm{Ca}, \mathrm{Na}$, and $\mathrm{K}$ were generated. The number concentration and size distribution were determined by scanning mobility particle sizer (SMPS), and a mode diameter of around $100 \mathrm{~nm}$ $\left(\mathrm{CaCl}_{2}\right)$ was detected (Fig. 4).

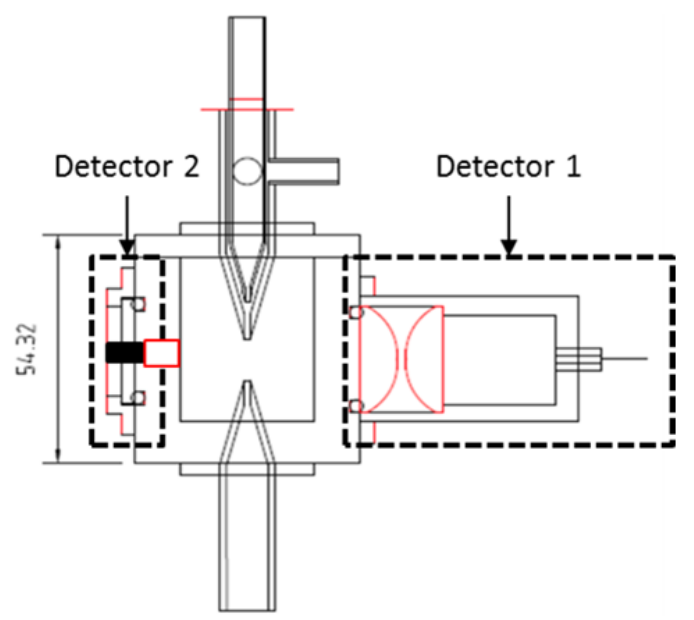

Fig. 2. Portable aerosol-LIBS chamber with two detectors.
Analysis of the LIBS system was affected by sampling the laboratory-produced particles in the portable aerosolLIBS chamber. Consequently, the emission lines (with a 100-shot average), which were not observed in the aerosolfree blank sample obtained from the HEPA filter, were formed as in Fig. 5.

The data revealed that the $\mathrm{P}, \mathrm{Fe}, \mathrm{Mg}, \mathrm{Cu}, \mathrm{Co}, \mathrm{Ni}, \mathrm{Ca}$,

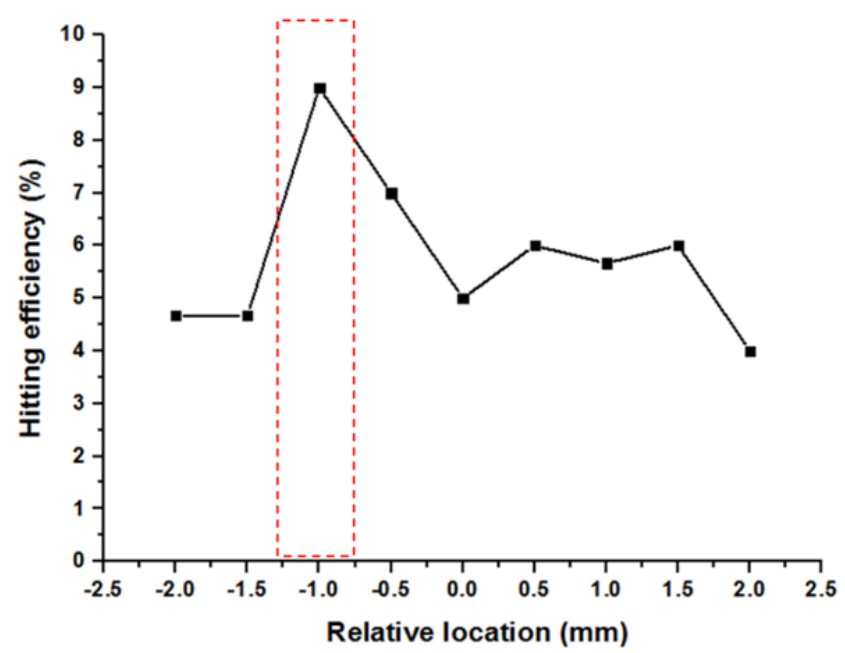

Fig. 3. Particle hitting efficiency with laser location.

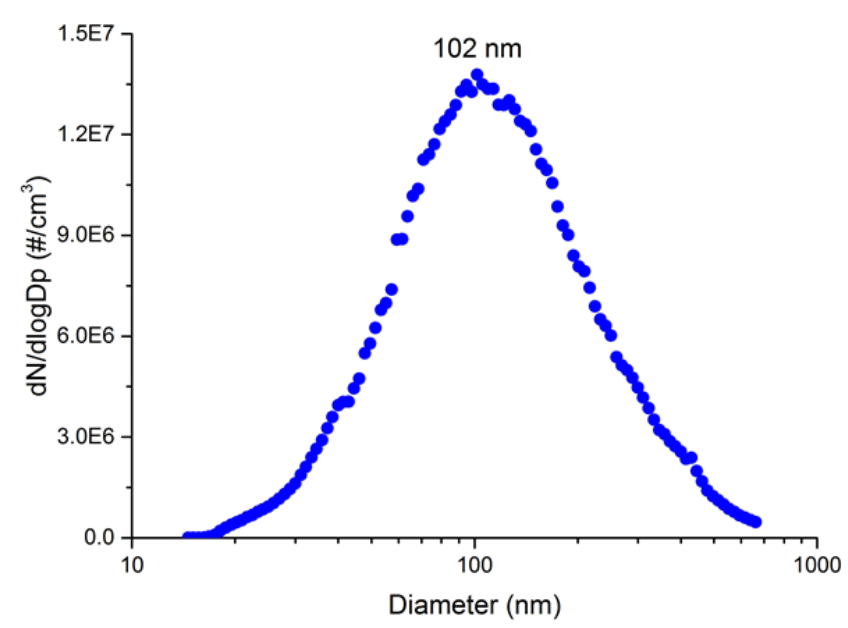

Fig. 4. Number size distribution of laboratory-generated aerosols $\left(\mathrm{CaCl}_{2}\right)$. 
(a)

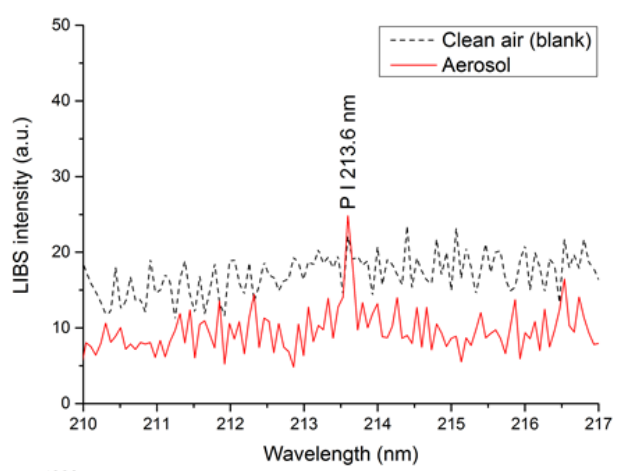

(c)

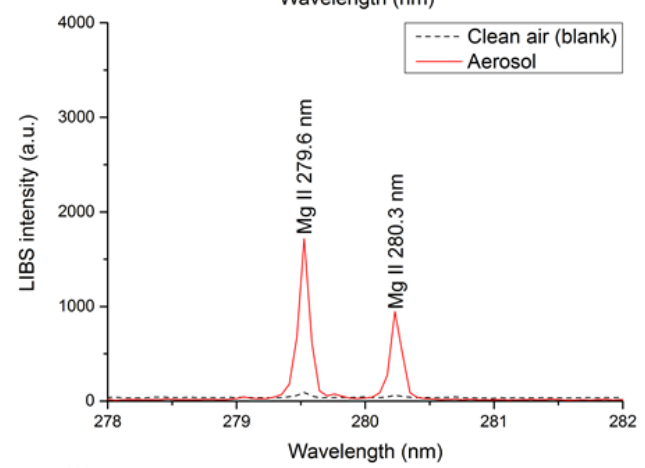

(e)

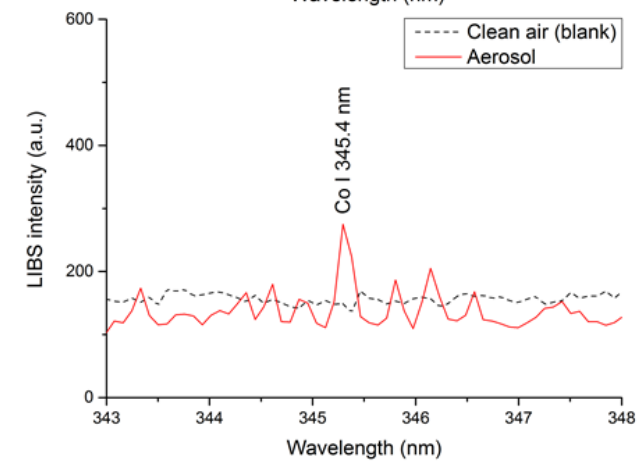

(g)

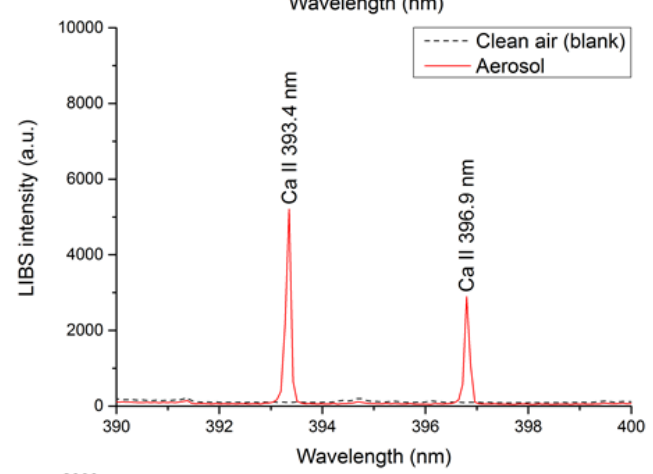

(i)

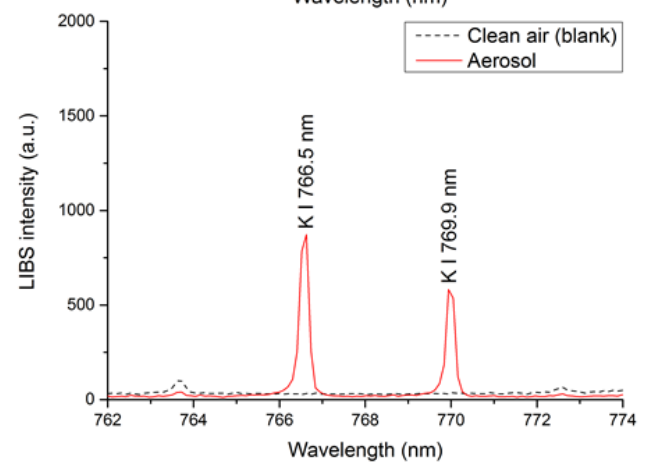

(b)

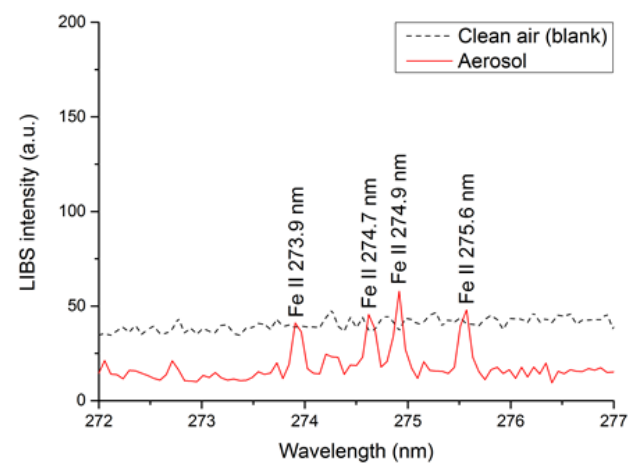

(d)

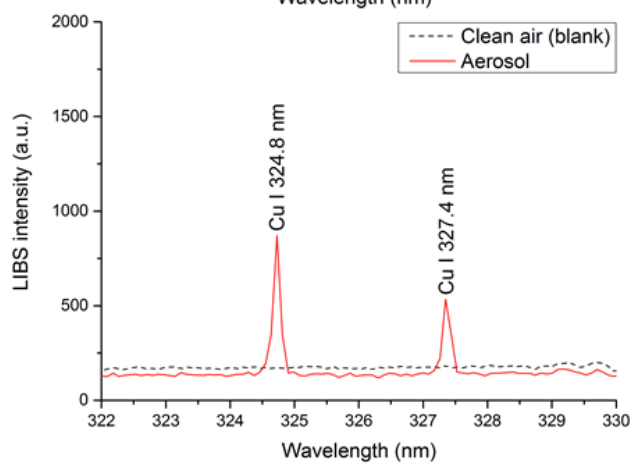

(f)

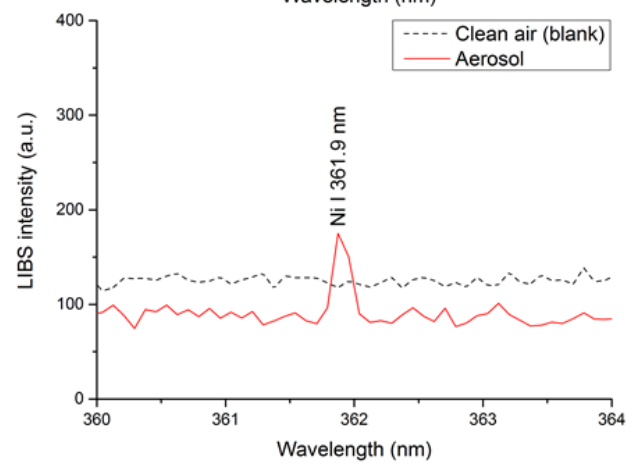

(h)

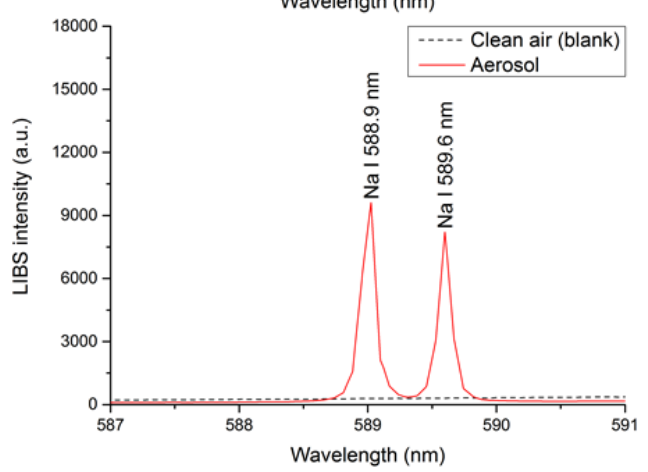

Fig. 5. LIBS spectra showing (a) $\mathrm{P}$, (b) $\mathrm{Fe}$, (c) $\mathrm{Mg}$, (d) $\mathrm{Cu}$, (e) $\mathrm{Co}$, (f) $\mathrm{Ni}$, (g) $\mathrm{Ca}$, (h) $\mathrm{Na}$, and (i) $\mathrm{K}$ in aerosol samples (100shot average). 
$\mathrm{Na}$, and $\mathrm{K}$ emission lines were detected in real time, in alignment with the element compositions detected in various laboratory-produced particles. The portable aerosol-LIBS chamber (Fig. 2) consists of two detectors. Detector 1 was designed to have a detection efficiency higher than that of Detector 2 by collimating and focusing the light emitted from the laser-induced plasma using two $30 \mathrm{~mm}$ focal length plano-convex lenses with diameters of $25.4 \mathrm{~mm}$. Detector 2 was coupled with a collimating lens (74-UV; Ocean Optics Inc., USA) with a focal length of $10 \mathrm{~mm}$ (diameter $=5 \mathrm{~mm}$ ). In comparison to Detector 1 , it required less space in terms of its design structure. As such, either Detector 1 or Detector 2 could be used selectively, depending on the detection sensitivity and space required for the installation. To determine whether the appropriate detection efficiency could be attained, in line with the design/production purposes mentioned above, we compared the emission lines of the laboratory-produced particle elements according to the different detectors under the same conditions (polydispersed aerosol number concentration: $20,000 \pm 1,600 \mathrm{~cm}^{-3}$ ). The results are presented in Fig. 6 .

The bar graph in Fig. 6 represents the mean value of the peak area of each element, obtained by analyzing 100 spectra, while the error bar indicates the standard deviation. For the peak area mean values of $\mathrm{Mg}, \mathrm{Cu}, \mathrm{Ca}, \mathrm{Na}$, and $\mathrm{K}$, a scale adjustment was necessary for comparison with the average values of the other elements. The value divisions are shown separately in parentheses. Although the detection efficiency varied according to each element (ranging from 1.1 to 3.9 ), the efficiency of Detector 1 was found to be higher than that of Detector 2 with regard to all elements, without exception. We measured the hitting rate in accordance with a number concentration of $200 \mathrm{~nm} \mathrm{CaCl}_{2}$ aerosol particles, using the relatively higher detection efficiency of Detector 1. The results are presented in Fig. 7.

\section{CONCLUSION}

Based on the real-time detection results of various

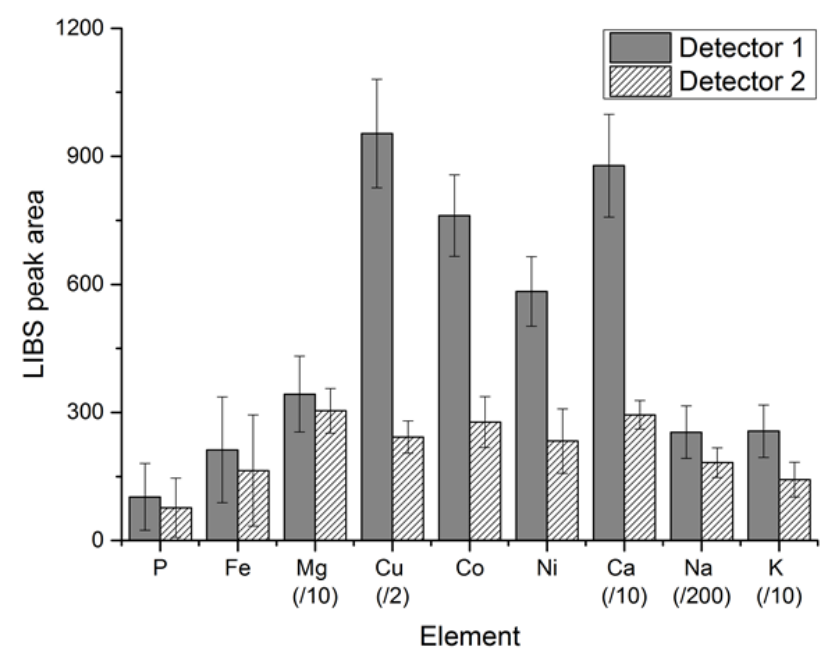

Fig. 6. Comparison of the LIBS peak areas between the two different detector systems.

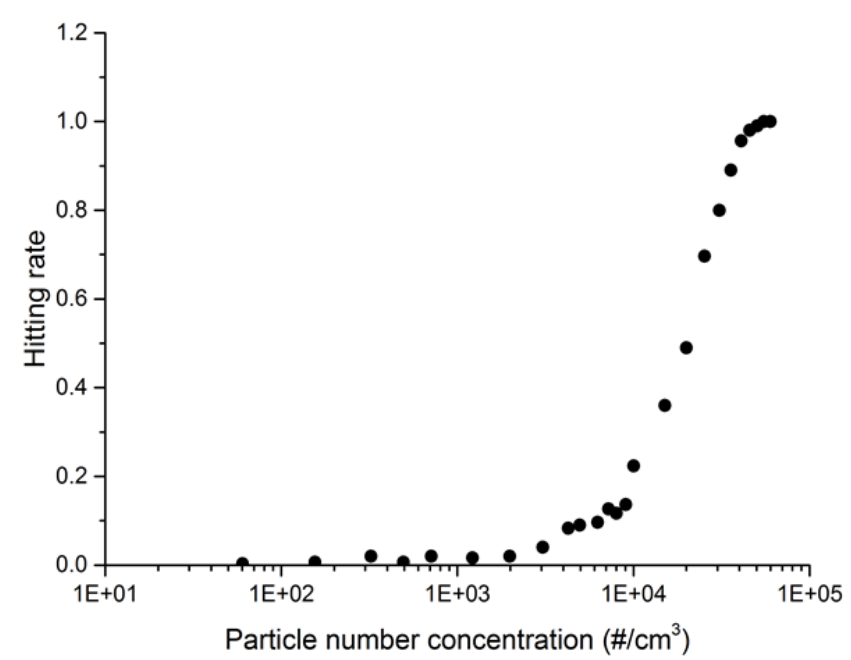

Fig. 7. Hitting rate for $200 \mathrm{~nm} \mathrm{CaCl}_{2}$ particles (Detector 1).

elemental components ( $\mathrm{P}, \mathrm{Fe}, \mathrm{Mg}, \mathrm{Cu}, \mathrm{Co}, \mathrm{Ni}, \mathrm{Ca}, \mathrm{Na}$, and $\mathrm{K})$, this study verified the potential of the LIBS technique for real-time monitoring of process-induced particles generated during semiconductor production. Identification of the chemical composition of contaminative particles in real-time may help to identify the source of such particles, thereby minimizing the occurrence of defective products. The aerosol-LIBS can be used in either free-firing mode or triggering mode, depending on the operational environment and purpose. The performance of the free-firing mode, as tested in this study, indicates that it can be easily used for practical application with a relatively simple measurement system configuration, and the detectors are constructed so that they can be selectively used according to the sensitivity requirements and installation. Various experiments aiming to optimize the analytical system and improve its performance are ongoing, with the goal of applying the aerosol-LIBS technique during the semiconductor production process.

\section{ACKNOWLEDGMENTS}

This work was supported by the National Leading Research Laboratory program (NRF2016R1A2A1A05005532) funded by the Ministry of Science, ICT, and Future Planning (MSIP) and also partially supported by Samsung Electronics.

\section{REFERENCES}

Alvira, F.C., Bilmes, G.M., Flores, T. and Ponce, L. (2015). Laser-induced breakdown spectroscopy (LIBS) quality control and origin identification of handmade manufactured cigars. Appl. Spectrosc. 69: 1205-1209.

Baltzinger, J. and Delahaye, B. (2010). Contamination monitoring and analysis in semiconductor manufacturing. In Semiconductor technologies, Grym, J. (Ed.), IntechOpen, UK, pp. 57-78.

Barefield, J.E., II, Judge, E.J., Campbell, K.R., Colgan, J.P., Kilcrease, D.P., Johns, H.M., Wiens, R.C., McInroy, R.E., Martinez, R.K. and Clegg, S.M. (2016). Analysis 
of geological materials containing uranium using laserinduced breakdown spectroscopy (LIBS). Spectrochim. Acta, Part B 120: 1-8.

Barreda, F.A., Trichard, F., Barbier, S., Gilon, N. and Saint-Jalmes, L. (2012). Fast quantitative determination of platinum in liquid samples by laser-induced breakdown spectroscopy. Anal. Bioanal.Chem. 403: 2601-2610.

Baudelet, M., Yu, J., Bossu, M., Jovelet, J., Wolf, J.P., Amodeo, T., Fŕjafon, E. and Laloi, P. (2006). Discrimination of microbiological samples using femtosecond laser-induced breakdown spectroscopy. Appl. Phys. Lett. 89: 163903.

Bendicho, C., Lavilla, I., Pena-Pereira, F. and Romero, V. (2012). Green chemistry in analytical atomic spectrometry: A review. J. Anal. At. Spectrom. 27: 1831-1857.

Chik, M.A., Saidin, M.H. and Hashim, U. (2010). Industrial engineering roles in semiconductor fabrication. $11^{\text {th }}$ Asia Pacific Industrial Engineering \& Management Systems Conference.

Cremers, D.A. and Radziemski, L.J. (2006). Handbook of laser-induced breakdown spectroscopy. John Wiley \& Sons, Ltd., USA.

Ferioli, F. and Buckley, S.G. (2006). Measurements of hydrocarbons using laser-induced breakdown spectroscopy. Combust. Flame 144: 435-447.

Gondal, M.A., Hussain, T., Yamani, Z.H. and Ahmed, Z. (2007). Determination of toxic metals in petroleum, cultivated land and ore samples using laser-induced breakdown spectroscopy. Bull. Environ. Contam. Toxicol. 78: 270-274.

Gottfried, J.L., De Lucia Jr, F.C., Munson, C.A. and Miziolek, A.W. (2008). Standoff detection of chemical and biological threats using laser-induced breakdown spectroscopy. Appl. Spectrosc. 62: 353-363.

Grifoni, E., Legnaioli, S., Lorenzetti, G., Pagnotta, S. and Palleschi, V. (2015). Applying LIBS to metals processing. Spectroscopy 30: 20-31.

Hahn, D.W. and Lunden, M.M. (2000). Detection and analysis of aerosol particles by laser-induced breakdown spectroscopy. Aerosol Sci. Technol. 33: 30-48.

Hahn, D.W. and Omenetto, N. (2012). Laser-induced breakdown spectroscopy (LIBS), Part II: Review of instrumental and methodological approaches to material analysis and applications to different fields. Appl. Spectrosc. 66: 347-419.

Harmon, R.S., Remus, J., McMillan, N.J., McManus, C., Collins, L., Gottfried Jr, J.L., DeLucia, F.C. and Miziolek, A.W. (2009). LIBS analysis of geomaterials: Geochemical fingerprinting for the rapid analysis and discrimination of minerals. Appl. Geochem. 24: 11251141.

Lee, H., Maeng, H., Kim, K., Kim, G. and Park, K. (2018). Application of laser-induced breakdown spectroscopy for real-time detection of contamination particles during the manufacturing process. Appl. Opt. 57: 3288-3292.
Lee, M. and Yook, S.J. (2015). Investigation of particulate contamination of heated wafers contained in a closed environment. J. Aerosol Sci. 88: 148-158.

Lennard, C., El-Deftar, M.M. and Robertson, J. (2015). Forensic application of laser-induced breakdown spectroscopy for the discrimination of questioned documents. Forensic Sci. Int. 254: 68-79.

López-Moreno, C., Palanco, S., Laserna, J.J., DeLucia Jr, F., Miziolek, A.W., Rose, J., Walters, R.A. and Whitehouse, A.I. (2006). Test of a stand-off laser-induced breakdown spectroscopy sensor for the detection of explosive residues on solid surfaces. J. Anal. At. Spectrom. 21: 5560.

Maeng, H., Chae, H., Lee, H., Kim, G., Lee, H., Kim, K., Kwak, J., Cho, G. and Park, K. (2017). Development of laser-induced breakdown spectroscopy (LIBS) with timed ablation to improve detection efficiency. Aerosol Sci. Technol. 51: 1009-1015.

Maurice, S., Clegg, S.M., Wiens, R.C., Gasnault, O., Rapin, W., Forni, O., Cousin, A., Sautter, V., Mangold, N., Le Deit, L., Nachon, M., Anderson, R.B., Lanza, N.L., Fabre, C., Payré, V., Lasue, J., Meslin, P.Y., Léveillé, R.J., Barraclough, B.L., Beck, P., Bender, S.C., Berger, G., Bridges, J.C., Bridges, N.T., Dromart, G., Dyar, M.D., Francis, R., Frydenvang, J., Gondet, B., Ehlmann, B.L., Herkenhoff, K.E., Johnson, J.R., Langevin, Y., Madsen, M.B., Melikechi, N., Lacour, J.L., Le Mouélic, S., Lewin, E., Newsom, H.E., Ollila, A.M., Pinet, P., Schröder, S., Sirven, J.B., Tokar, R.L., Toplis, M.J., D'Uston, C., Vaniman, D.T. and Vasavada, A.R. (2016). ChemCam activities and discoveries during the nominal mission of the Mars Science Laboratory in Gale crater, Mars. J. Anal. At. Spectrom. 31: 863-889.

Park, K., Cho, G. and Kwak, J.H. (2009). Development of an aerosol focusing-laser induced breakdown spectroscopy (aerosol focusing-LIBS) for determination of fine and ultrafine metal aerosols. Aerosol Sci. Technol. 43: 375386.

Park, S.H., Kim, S. and Baek, J.G. (2018). Kernel-densitybased particle defect management for semiconductor manufacturing facilities. Appl. Sci. 8: 224.

Srungaram, P.K., Ayyalasomayajula, K.K., Yu-Yueh, F. and Singh, J.P. (2013). Comparison of laser induced breakdown spectroscopy and spark induced breakdown spectroscopy for determination of mercury in soils. Spectrochim. Acta, Part B 87: 108-113.

Yamamoto, K.Y., Cremers, D.A., Ferris, M.J. and Foster, L.E. (1996). Detection of metals in the environment using a portable laser-induced breakdown spectroscopy instrument. Appl. Spectrosc. 50: 222-233.

Received for review, August 23, 2018 Revised, August 23, 2018 Accepted, September 4, 2018 